Article

\title{
Neighborhood Environment, Lifestyle, and Health of Older Adults: Comparison of Age Groups Based on Ecological Model of Aging
}

\author{
Zhenhua Zheng (i) and Liu (Lydia) Yang *(i) \\ Center for Population and Development Policy Studies, Fudan University, 220 Handan Road, Shanghai 200433, \\ China; zhengzhenhua@fudan.edu.cn \\ * Correspondence: liu.yang@fudan.edu.cn; Tel.: +86-1338-750-4578
}

Received: 9 March 2019; Accepted: 3 April 2019; Published: 8 April 2019

check for updates

\begin{abstract}
Worldwide population aging is currently in acceleration, which is especially true for China. Echoing the advocacy of "active aging" and "age-friendly communities", governments and researchers across the world are paying more attention to the impact of neighborhoods on the health of older adults. Using the Ecological Model of Aging, this study aimed to discuss the relationships between neighborhood environment, lifestyle, and health of older adults, and to compare the differences among older adults of different age groups. The results showed that landscape environment has a direct effect on the health of older adults, while leisure environment has an indirect effect through lifestyle. Both leisure environment and landscape environment directly encourage older adults to take part in outdoor activity, in which the former mainly promotes the social participation of the high-aged (aged $80+$ ) group, while the latter merely promotes that of the middle-aged (aged 70-79) group. The positive effect of social participation on health is gradually strengthened with the increase of age. Meanwhile, outdoor activity has its greatest effect on the middle-aged (aged 70-79) group, but not the low-aged (aged 60-69) group. To effectively boost the health of older adults and promote active aging, adequate considerations should also be given to the differentiated demands of older adults of different age groups, optimization of neighborhood environment, as well as cultivation of an amicable atmosphere.
\end{abstract}

Keywords: health of older adults; neighborhood environment; age group; social participation; outdoors activity; mediating role

\section{Introduction}

With the acceleration of population aging all over the world, the views of international society concerning this issue have shifted from "successful aging" to "healthy aging" and then to "active aging". Due to the growing proportion of the aging population in the global population, the role of older adults should be transformed from "passive dependents" into "active participants" of social activities. Active aging encourages older adults to positively face life, maintain physical and mental health, participate in social development, realize self-value, and shift their focus from longevity to quality of life [1]. The concepts of "age-friendly cities" and "age-friendly communities" were subsequently proposed with the aim to urge and help the governments to improve the community environment, which would promote the outdoor activities and social participation of older adults to boost their health [2]. "Age-friendly communities" highlighted the importance of communities as the main activity site and living space for older adults, as well as the practical value of community optimized intervention for active aging [3]. In recent years, increased attention has been paid to how the community environment affects health of the elderly [4]. 
In reality, the concept of "age-friendly communities" originated from the Ecological Model of Aging in environmental gerontology [5]. The model provided a general framework for comprehending the influence of environment on actions and welfare of older adults [6]. In brief, the Ecological Model of Aging assumed that the dynamic influences among people, physical environment, behavior, and quality of life, which constitute the living ecosystem of older adults [7]. Based on extensive studies on the relation between neighborhood environment and older adults' health $[8,9]$, an increasing number of researchers start to focus on the Ecological Model of Aging [6,7].

Studies on health must be multi-dimensional [10]. The impact of neighborhood environment on older adults' health is not isolated. Instead, it affects the health of older adults by influencing their lifestyle and behaviors. In particular, outdoor activity is deemed to play the most prominent and distinctive facilitating role in the older adults' health. Therefore, most research lists outdoor activity as a mediator of the relationships between neighborhood environment and older adults' health [11,12]. Although social participation was used as a mediator in few studies, it has received increasing attention due to its importance to active aging [13,14]. According to existing literatures, scholars studied from different perspectives on the relationships between neighborhood environment, lifestyle, and health of older adults, and have achieved fruitful results. However, few studies regarded the different dimensions of lifestyle, such as outdoor activities and social participation, as mediators simultaneously.

For the older adults living in the communities, the influence of environment on health involves a complex path from neighborhood environment to lifestyle and then to health. Furthermore, there are significant differences in physiological functions, behavioral habits, and psychological status among the older adults at different age stages, which lead to different factors affecting their health. Thus, it is of practical significance to explore the effects of neighborhood environment on the health of older adults according to specific age sub-groups.

In the recent years, China is encountering the largest and fastest population aging in the world [15]. Shanghai, the economic and financial center of China, is also one of the cities with the fastest rate of population aging. Older adults aged 65 or above account for $14.5 \%$ of the total population of Shanghai. It is predicted that the figure will be increased to around $20 \%$ till 2030 [16]. Consequently, it is of great importance to explore how the neighborhood environment acts on older adults' health and age-friendly community construction in Shanghai and even whole China.

In this study, a conceptual model of "neighborhood environment-lifestyle-health of older adults" was constructed first. Then, we examined the role of lifestyle in mediating neighborhood environment and elderly health, based on the data collected from a survey in Shanghai. Moreover, differences in mediating effects of lifestyle among the older adults at different age stages were explored. The conclusions provide valid support for the formulation of related urban public policy, fine design, and implementation of urban planning, as well as aging-oriented community construction proposals.

\section{Theoretical Model and Hypotheses}

\subsection{Theoretical Model}

The Ecological Model of Aging was proposed by Lawton and Nahemow in 1973 [5]. It is the primary theoretical concept of environmental gerontology, devoted to exploring the behavioral, physical, and psychological influences of encounters between older adults and the environment they live in [17]. As for the older adults living in communities, their ecosystem is composed of multiple factors including older adults themselves, neighborhood environment, older adults' lifestyle or the mode of activity, and the older adults' health. It emphasizes not only the significance of neighborhood environment to older adults' health, but also the combined effect of their lifestyle in this ecosystem $[7,18]$.

Neighborhood environment reflects the tangible infrastructure inside the neighborhoods [19]. Although researchers have different opinions on the measurement of neighborhood environment, leisure environment and landscape environment are generally regarded as its two most important 
aspects [20,21]. To be specific, Leisure environment mainly includes the layout of the fitness facilities and the barrier-free facilities, etc., which shows the support capability of neighborhood outdoor space for the residents' outdoor activities or communications [22]. Landscape environment covers the architectural aesthetics, green, tidiness, and maintenance of the neighborhood [23], which reflects the support for the visual and sensory comfort of the neighborhood residents [24]. Leisure environment and landscape environment provide support for older adults in different aspects and have different effects on their health. Therefore, it is necessary to discuss them separately.

Lifestyle is an integral research object in sociology. In this study, it primarily refers to the healthy lifestyle, that is, a series of behaviors of maintaining and improving health conditions generated by the individual motivation and ability [25]. In fact, outdoor activity and social participation are both important parts of the healthy lifestyle, as well as key factors affecting the health of older adults in the overall community ecosystem that can promote active aging. Therefore, inclusion of both outdoor activity and social participation into one ecological model for comparative analysis will make the study more systematic and comprehensive.

Moreover, some studies on community ecosystems ignored the correlation and interaction between the different dimensions of lifestyle. In fact, outdoor activity and social participation do not act on the health of older adults independently; instead, they interact with each other in the community ecosystem. Social participation can lead to more outdoor activities and social interactions, thereby improving the health of older adults [26]. In view of the above, we constructed an ecological model of "neighborhood environment-lifestyle-health of older adults", as shown in Figure 1. This model framed the main hypotheses in this study, which are introduced in Section 2.2. Hypotheses.

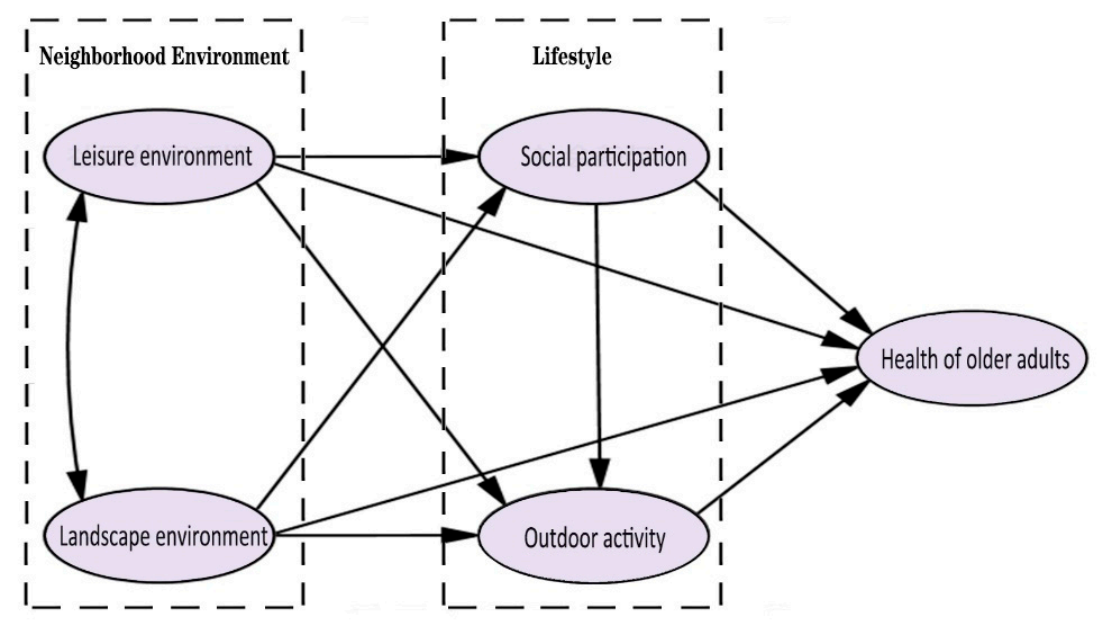

Figure 1. The conceptual model of "neighborhood environment-lifestyle—-health of older adults".

The structural equation model (SEM) combines factor analysis with path analysis, showing an edge over the quantitative research on multi-variable interaction and group comparison. Therefore, this study adopted SEM to analyze the complex relations among the health, lifestyle, and neighborhood environment of older adults in different age groups. Group comparison of SEM was employed to examine whether there are significant differences between different groups, which can make the results rigorous, intuitive, and explicit.

\subsection{Hypotheses}

Many previous studies have confirmed that the better the leisure environment or landscape environment is, the healthier status the older adults will be [8,27-30]. Moreover, social participation can make older adults feel respected and recognized [31] and benefit their health [32-35]. Outdoor activity has also been proved to be good for elderly health [36-41]. Therefore, this study paid more attention to the complex relations between the variables in the ecological model. Specifically, the mediating 
effects of social participation and outdoor activities on the relationship between neighborhood environment and health of older adults, and the differences among various age groups of the older adults were examined.

Studies of human behavior and social environment in sociological theory consider that social environment plays a crucial role in human lifestyle [42]. The structural theory endows outdoor environment with social meaning which deems that human behaviors and social interaction normally take place in specific spatial environment. People under different neighborhood environments would choose different types of activity, and high-quality outdoor environment would stimulate more outdoor activities [43-47] and social participation [48,49].

With the development of environmental gerontology and age-friendly communities, more and more researchers regarded a neighborhood as an ecosystem [50]. The relationship between the neighborhood environment and the health of older adults is not simply linear, but also influenced by the lifestyle in the neighborhood ecosystem. Due to their promotion of "active aging", outdoor activities and social participation have received increasing attention.

Outdoor activity as a mediator of the relationships between neighborhood environment and elderly health has been reported [11,12,51-53]; however, the difference in its effects in mediating the relationships between elderly health and the two different dimensions of neighborhood environment has rarely been systematically compared. To clarify the paths of different dimensions of neighborhood environment affecting health of older adults, the following hypotheses are proposed.

Hypothesis 1 (H1). Outdoor activity serves as a mediator of relationship between leisure environment and health of older adults.

Hypothesis 2 (H2). Outdoor activity serves as a mediator of relationship between landscape environment and health of older adults.

Rare studies have regarded social participation as a mediator of the relation between neighborhood environment and older adults' health. Although several researchers have dealt with the impact of social participation on the welfare of the elderly in the neighborhood environment $[13,14,28]$, systematic studies are still lacking. Accordingly, we proposed hypotheses as follows.

Hypothesis 3 (H3). Social participation serves as a mediator of relationship between leisure environment and health of older adults.

Hypothesis 4 (H4). Social participation serves as a mediator of relationship between landscape environment and health of older adults.

Furthermore, from an ecological perspective, outdoor activity and social participation will also interact in the neighborhood ecosystem, rather than acting solely on the elderly health. More social participation can lead to more outdoor activity, which in turn benefits the health. Therefore, we propose the last hypothesis.

Hypothesis 5 (H5). Outdoors activity serves as a mediator of relationship between social participation and health of older adults.

\section{Materials and Methods}

\subsection{Sampling}

To explore the relations between neighborhood environment and health of older adults, Fudan University conducted a neighborhood survey on the health of older adults living in the communities in 
Xinhua Sub-district, Changning District of Shanghai in June 2014. Xinhua Sub-district includes 17 residence districts with a coverage of $2.2 \mathrm{~km}^{2}$ and a population of around 78,000 residents. The population of older adults aged 60 or above accounts for $20.2 \%$. The two-stage sampling method is adopted here. At first, the diversified geographical location, transportation convenience, and the completion year were taken as the sampling evidence. In this study, we chose 43 neighborhoods from 198 neighborhoods in 17 residence districts as shown in Figure 2. The second step is to acquire the list of older adults aged 60 or above in 43 neighborhoods from the community committee. For communities with less than 120 older adults aged above 60 , the present research investigates all older adults without cognitive disorder; for communities with more than 120 older adults of the same age, the research takes the pure random sampling method to investigate 120 older adults without cognitive disorder. The paper altogether collects 2839 samples, removes 56 invalid samples, and finally preserves 2783 valid samples. The details are shown in Table 1.

Table 1. Description of the neighborhood samples.

\begin{tabular}{|c|c|c|c|c|c|c|}
\hline Location & No. & Neighborhoods & $\begin{array}{c}\text { Year of } \\
\text { Completion }\end{array}$ & $\begin{array}{l}\text { Housing Unit } \\
\text { Price (RMB) }\end{array}$ & $\begin{array}{c}\text { Number of } \\
\text { Floors }\end{array}$ & $\begin{array}{c}\text { Number of } \\
\text { Samples }\end{array}$ \\
\hline \multirow{3}{*}{ Xizhen } & 1 & Youlie Mansion & 2004 & 70,640 & 31 & 51 \\
\hline & 2 & Donghu Garden & 2003 & 72,383 & 20 & 27 \\
\hline & 3 & Xizhen Neighborhood & 1990 & 68,185 & 6 & 75 \\
\hline \multirow{3}{*}{ Yangzhai } & 4 & Xinhua Century Park & 2003 & 80,655 & 20 & 120 \\
\hline & 5 & Zhiyin Neighborhood & 1991 & 70,696 & 7 & 35 \\
\hline & 6 & Shenya New Mansion & 2002 & 76,860 & 30 & 26 \\
\hline \multirow{3}{*}{ Mei'an } & 7 & Kaixin Garden & 2002 & 56,013 & 21 & 55 \\
\hline & 8 & Meiquan Villa & 1996 & 220,782 & 2 & 15 \\
\hline & 9 & Mei'an Neighborhood & 1993 & 73,929 & 6 & 82 \\
\hline \multirow{2}{*}{ Xinhua } & 10 & Wenyuancun & 1999 & 71,584 & 4 & 94 \\
\hline & 11 & Xinhua House & 2001 & 79,983 & 7 & 77 \\
\hline \multirow{3}{*}{ Zuojiazhai } & 12 & Zhongyin Huaihai Garden & 1999 & 72,348 & 24 & 44 \\
\hline & 13 & Huaihai Garden & 2001 & 77,381 & 26 & 24 \\
\hline & 14 & Changfeng Pujiang & 1997 & 52,135 & 32 & 78 \\
\hline \multirow{2}{*}{ Xianghua } & 15 & Baihuacun & 1986 & 71,031 & 6 & 120 \\
\hline & 16 & $\begin{array}{l}\text { Xianghuaqiao } \\
\text { Neighborhood }\end{array}$ & 1988 & 66,345 & 6 & 70 \\
\hline \multirow{2}{*}{ Fanyu } & 17 & Jingcai Mansion & 2000 & 76,861 & 28 & 62 \\
\hline & 18 & Haifu Apartment & 1999 & 65,956 & 24 & 120 \\
\hline \multirow{2}{*}{ Xingfu } & 19 & 385 Alley, Fanyu Road & 1991 & 72,771 & 6 & 104 \\
\hline & 20 & Youyicun & 1991 & 70,640 & 6 & 86 \\
\hline \multirow{2}{*}{ Niuqiao } & 21 & Fanyu Mansion & 1993 & 56,952 & 29 & 78 \\
\hline & 22 & 222 Alley, Fanyu Road & 1993 & 57,131 & 7 & 69 \\
\hline \multirow{3}{*}{ Hongzhuang } & 23 & Shenxin Garden & 1980 & 75,182 & 18 & 84 \\
\hline & 24 & Hongfa Garden & 1997 & 79,941 & 20 & 78 \\
\hline & 25 & $\begin{array}{l}\text { Hongzhuang } \\
\text { Neighborhood }\end{array}$ & 1991 & 75,160 & 18 & 21 \\
\hline \multirow{2}{*}{ Dongzhen } & 26 & Huashan Garden & 2001 & 81,857 & 26 & 88 \\
\hline & 27 & Pingwu Neighborhood & 1990 & 73,285 & 19 & 69 \\
\hline \multirow{3}{*}{ Heping } & 28 & Heping Neighborhood & 1988 & 65,096 & 7 & 36 \\
\hline & 29 & Xingfu Neighborhood & 1987 & 63,967 & 6 & 64 \\
\hline & 30 & Shengyuan Mansion & 1997 & 61,456 & 23 & 36 \\
\hline \multirow{3}{*}{ Zhangjiazhai } & 31 & Zhangjia-zhai & 1998 & 63,383 & 6 & 33 \\
\hline & 32 & 722Alley Jiangsu Road & 1996 & 63,856 & 7 & 60 \\
\hline & 33 & Jiaxin City Garden & 1998 & 69,263 & 16 & 68 \\
\hline \multirow{3}{*}{ Tiandu } & 34 & Contemporary Xinhua & 2001 & 71,742 & 18 & 24 \\
\hline & 35 & Tiandu Neighborhood & 1997 & 70,997 & 6 & 60 \\
\hline & 36 & Kaixuan Apartment & 1997 & 69,714 & 8 & 84 \\
\hline
\end{tabular}


Table 1. Cont.

\begin{tabular}{lllcccc}
\hline Location & No. & \multicolumn{1}{c}{ Neighborhoods } & $\begin{array}{c}\text { Year of } \\
\text { Completion }\end{array}$ & $\begin{array}{c}\text { Housing Unit } \\
\text { Price (RMB) }\end{array}$ & $\begin{array}{c}\text { Number of } \\
\text { Floors }\end{array}$ & $\begin{array}{c}\text { Number of } \\
\text { Samples }\end{array}$ \\
\hline \multirow{3}{*}{ Renmin } & 37 & Modern Garden & 2003 & 77,935 & 29 & 63 \\
& 38 & Yan'an Apartment & 1986 & 69,870 & 14 & 73 \\
& 39 & Huayun Building & 1991 & 61,497 & 16 & 20 \\
\hline \multirow{4}{*}{ Tai'an } & 40 & Xinguoming Park & 2001 & 119,168 & 5 & 65 \\
& 41 & Tai'an 120 & 1996 & 263,717 & 3 & 71 \\
& 42 & Huashan Garden & 1995 & 80,978 & 28 & 120 \\
\hline
\end{tabular}

Notes: Housing unit price was retrieved from “https://sh.lianjia.com/” in December 2018.

Comparing samples in "Neighborhood Survey of Elderly Health in Communities" with samples aged over 60 in Shanghai City in the sixth national population census 2010, it can be found that the two have basically the identical age distribution trend. In consequence, it can be fitly judged that samples of the research well represent older adults in Shanghai City.

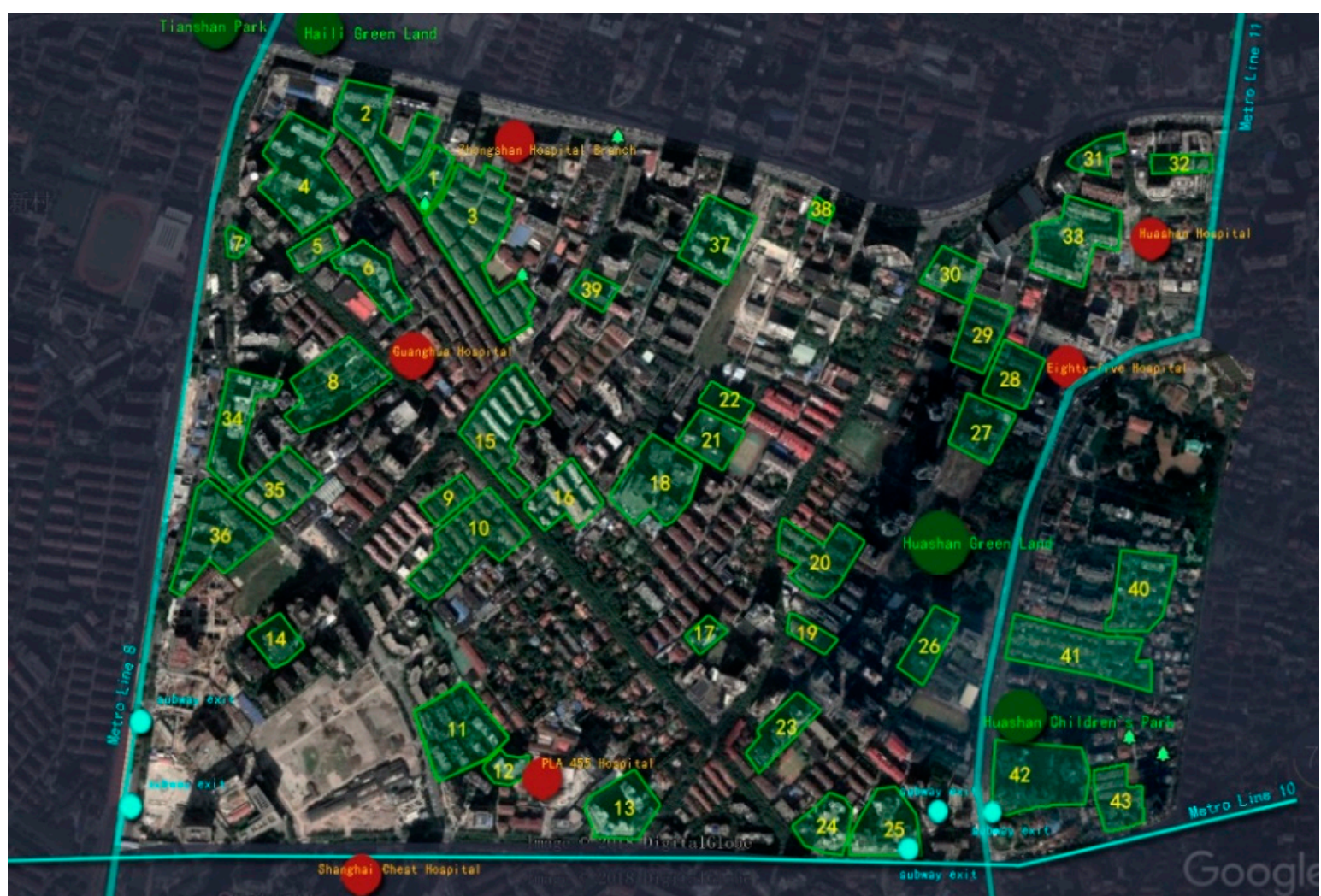

Figure 2. Map of the neighborhood samples.

\subsection{Variables}

\subsubsection{The Dependent Variable}

Self-rated health has been widely applied in the self-perceived health condition $[54,55]$ owing to its high predictability of the functional disability, morbidity and mortality [56]. Therefore, it is deemed as an ideal indicator used to assess objective health conditions [57]. According to Maddox et al. [58], subjective assessment of health as a means of health measurement outweighs practical medical measurement. This study takes the self-rated health method to measure older adults' health conditions and assess older adults" self-rated health by the question "How do you assess your general health 
condition?" Respondents are required to grade their health conditions from one point to five points, where higher points mean better health conditions.

\subsubsection{The Independent Variable}

Regarding the measurement of leisure environment and landscape environment, this study adopts two measurement models concerning neighborhood perceived environment developed by Mujahid et al. [24]. Leisure environment includes "walking convenience inside the neighborhood", "an environment suitable for walking", "adequate trees inside the neighborhood", "exercise opportunities", "enough sports facilities", "residents attracted to take a walk" and "residents attracted to do exercise". Landscape environment incorporates "interesting architecture inside the neighborhood", "clean and tidy environment", "attractive environment", "well maintenance of architecture and houses", and "favorable acoustic environment". All items fall into five grades from one point to five points, successively indicating "totally disagree", "disagree", "neutral", "agree", and "totally agree". Higher points signify higher approval of respondents for leisure environment and landscape environment.

\subsubsection{The Mediating Variable}

This study contains two mediating variables, namely social participation and outdoors activity. Social participation is assessed by respondents' participation frequency in five different activities during the past 12 months, including the interest group, community activity, the lecture, the mutual-help group, and the volunteer. All items are split into five grades from one point to five points, successively manifesting "never", "a few times per year", "a few times per month", "once a week" and "twice or three times per week". Higher points represent respondents' higher social participation degrees.

Outdoors activity consists of two observable variables, namely walking frequency and walking duration. In particular, walking frequency indicates respondents' times of walking per week, and walking duration signifies respondents' times of walking per time.

\subsubsection{The Control Variable}

While examining the relation among neighborhood environment, lifestyle, and health of older adults, we should pay attention to older adults' socio-economic status. Therefore, this research incorporates the income level and the education level into the conceptual model as control variables. Monthly income level falls into six levels. The assignment of each level is " $<1500 \mathrm{RMB}=1$, $1500-2500 \mathrm{RMB}=2,2500-3500 \mathrm{RMB}=3,3500-4500 \mathrm{RMB}=4,4500-5500 \mathrm{RMB}=5$, and $>5500 \mathrm{RMB}$ $=6$ " in sequence. The education level is split into five levels. The assignment of each level is " $1=$ the junior high school and below, 2 = the senior high school, the technical secondary school, and the technical school, $3=$ the junior college, $4=$ the undergraduate, and $5=$ the master and above", respectively. ( 1 USD $=6.9066$ RMB. Cited at 19:45 on 1 February 2019 from Bank of China. Available via http:/ /srh.bankofchina.com/search/whpj/search.jsp).

\subsection{Reliability, Validity, the Fitness Test, and Model Optimization}

The test results of all observable variables in the high score and low score group are significant (the high score group and the low score group are differentiated by 27 quantile and 73 quantile) with excellent discriminability. As the number of samples in the research totals $2783(>1000)$ and samples approximately conform to normal distribution, sample data in the present research is suitable for SEM analysis. 
By performing multi-factor confirmatory analysis on all measurement models in the conceptual model, this study finds that the load capacity of observable variable noise environment and maintenance conditions in the landscape environment measurement model are not up to 0.6 . Accordingly, another multi-factor confirmatory analysis is made after deleting the two observable variables. The composite reliability of all adjusted measurement models is above 0.6 ; mean variance extraction quantity is over 0.5 ; observable variable factor load capacity is above 0.6 and the reliability coefficient is above 0.36 . All measurement models are fit for SEM analysis because of good reliability and validity.

As indicated by model fitting output results, GFI (goodness-of-fit index), AGFI (adjusted goodness-of-fit index) and RMSER (root mean square error of approximation) met the ideal criterion, while the $\mathrm{X}^{2} / \mathrm{DF}$ (ratio of chi-square to degree of freedom), IFI (incremental fit index) and CFI (comparative fit index) did not. It suggested the necessity to optimize the model. Model fitting output results demonstrate that the value of revised index between residual of "residents attracted to take a walk" (e4) and residual of "residents attracted to do exercise" (e5) was maximum. Due to the co-variation relation between the two, the chi-square value can be reduced by 57.112 at least. Subsequently, the co-variation relation between e4 and e5 was set up for the model fitting, then IFI, $\mathrm{CFI}$ and $\mathrm{X}^{2} / \mathrm{DF}$ did not meet the ideal criterion. Therefore, model still needed to be optimized. After setting up the co-variation relation between residual e2 and e3, as well as e10 and e11, we found that all index met the ideal criterion. Therefore, the optimized model had favorable fit goodness. Table 2 shows more details.

Table 2. Comparison of the fit index before and after model optimization.

\begin{tabular}{ccccccc}
\hline & GFI & AGFI & IFI & CFI & RMSEA & X $^{2} /$ DF \\
\hline Pre-optimization model & 0.929 & 0.913 & 0.843 & 0.842 & 0.063 & 6.013 \\
Post-optimization model & 0.948 & 0.946 & 0.902 & 0.901 & 0.045 & 3.777 \\
Ideal criterion & $>0.9$ & $>0.9$ & $>0.9$ & $>0.9$ & $<0.08$ & $<5.0$ \\
\hline
\end{tabular}

\section{Results}

\subsection{Descriptive Statistics of Variable}

Among the 2783 valid samples of older adults, there are 1163 of male and 1620 of female, in which the gender proportion is consistent with the national level. As for the division of the aging stage, the international society tends to take 60 or 65 as the benchmark of the aging population, while the scholars in China usually divide the older adults into three age groups: low-aged group (persons aged 60-69), middle-aged group (persons aged 70-79) and high-aged group (persons aged 80 or above) [59]. Consequently, this study followed this criterion to sort all samples, finally obtaining 1292 of low-aged (aged 60-69) group, 964 of middle-aged (aged 70-79) group, and 527 of high-aged (aged 80+) group. The self-rated health of older adults gradually decreases with age. The mean values of the scores of items of leisure environment and landscape environment showed little differences among various age groups. Table 3 shows more details. 
Table 3. Characteristics of variables.

\begin{tabular}{|c|c|c|c|c|c|c|}
\hline \multirow{2}{*}{ Latent Variables } & \multirow{2}{*}{ Observable Variables } & \multirow{2}{*}{ Items } & \multicolumn{4}{|c|}{ Mean Scores of Items } \\
\hline & & & All Samples & Low-Aged & Middle-Aged & High-Aged \\
\hline Health of older adults & self-rated health & Your general health condition & 2.35 & 2.52 & 2.26 & 2.08 \\
\hline \multirow{6}{*}{ Leisure environment } & Suitability for walking & It is a pleasant thing to take a walk in the neighborhood & 3.31 & 3.33 & 3.28 & 3.32 \\
\hline & Exercise opportunities & $\begin{array}{l}\text { Our neighborhood affords many opportunities to do } \\
\text { exercise }\end{array}$ & 3.00 & 3.02 & 2.94 & 3.05 \\
\hline & Adequate trees & Trees inside the neighborhood provide enough shade & 3.14 & 3.11 & 3.11 & 3.25 \\
\hline & Attracted to take a walk & I often see others walking in the neighborhood & 3.32 & 3.27 & 3.32 & 3.45 \\
\hline & Attracted to do exercise & I often see others doing exercise in the neighborhood & 3.18 & 3.16 & 3.17 & 3.27 \\
\hline & Sports facilities & Our neighborhood provides lots of sports facilities & 2.95 & 2.97 & 2.89 & 2.98 \\
\hline \multirow{3}{*}{ Landscape environment } & Attraction & Our neighborhood is very attractive & 2.92 & 2.92 & 2.95 & 2.68 \\
\hline & Tidy and clean & $\begin{array}{l}\text { There are lots of garbage and waste on roads inside the } \\
\text { neighborhood }\end{array}$ & 3.61 & 3.61 & 3.58 & 3.65 \\
\hline & Interesting architecture & $\begin{array}{l}\text { Architecture and houses inside our neighborhood are } \\
\text { interesting }\end{array}$ & 2.72 & 2.72 & 2.70 & 2.76 \\
\hline \multirow{5}{*}{ Social participation } & Interest group & Frequency of joining in outdoor interest groups & 1.87 & 1.92 & 1.89 & 1.47 \\
\hline & Community activity & $\begin{array}{l}\text { Frequency of joining in community cultural or sports } \\
\text { activities }\end{array}$ & 1.76 & 1.77 & 1.77 & 1.41 \\
\hline & Lecture & Frequency of listening to lecture or report & 1.65 & 1.65 & 1.71 & 1.43 \\
\hline & Mutual-help group & $\begin{array}{l}\text { Frequency of joining in self-management or mutual-help } \\
\text { group }\end{array}$ & 1.50 & 1.45 & 1.53 & 1.38 \\
\hline & Volunteer & Frequency of joining in volunteer work & 1.64 & 1.72 & 1.68 & 1.23 \\
\hline \multirow{2}{*}{ Outdoor activity } & Walking frequency & $\begin{array}{l}\text { Times of walking per week (just recording the times of } \\
\text { walking lasting for at least ten minutes) }\end{array}$ & 4.20 & 4.50 & 3.58 & 3.44 \\
\hline & Walking duration & $\begin{array}{l}\text { Duration of walking per time (just recording the times of } \\
\text { walking lasting for at least ten minutes) }\end{array}$ & 28.6 & 31.25 & 28.7 & 22.5 \\
\hline \multirow{2}{*}{ Control variable } & income & Monthly income per person of your family & 3.33 & 3.30 & 3.42 & 3.22 \\
\hline & education & Your level of education & 2.24 & 2.17 & 2.51 & 1.95 \\
\hline
\end{tabular}




\subsection{Comparison of Model Paths of Older Adults in Different Age Groups}

Regardless of the influence of factor load capacity, the model sets up the same path coefficient for the low-aged (aged 60-69) group, the middle-aged (aged 70-79) group and the high-aged (aged $80+$ ) group. As shown in Figures 3-5, there exists significant discrepancy among the three age groups in terms of the model path. Consequently, it is necessary to compare the varying influence of the independent variable on the dependent variable in different age groups. Table 4 presents detailed model fitting results of different age groups.

Table 4. Group comparison of total effect, direct effect, and indirect effect.

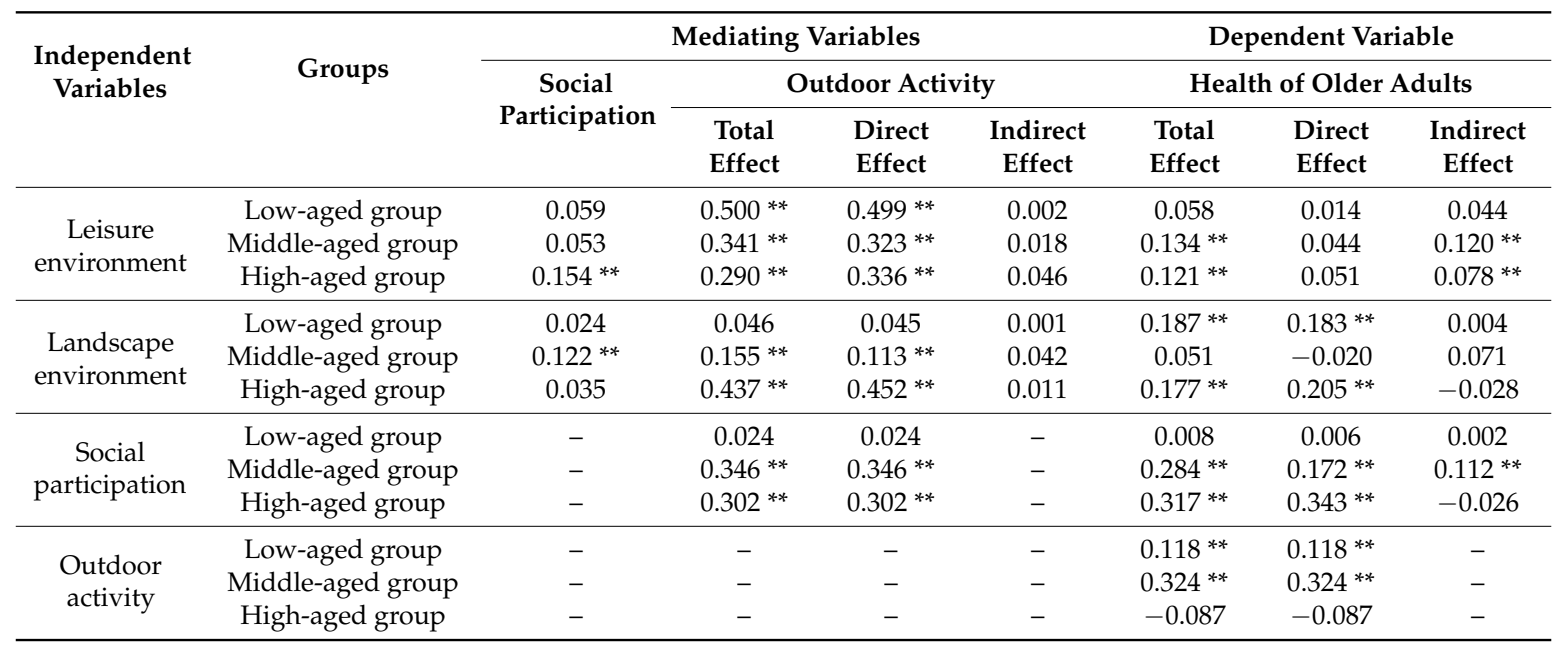

${ }^{* * *}$ means significant at the 0.01 confidence level; ${ }^{* *}$ means significant at the 0.05 confidence level; the significance test chooses the Percentile $95 \%$ confidence interval two-tailed test method. In case of any mediating variable in the model, the influence of the independent variable on the dependent variable can be divided into "total effect", "direct effect" and "indirect effect". In particular, total effect is the sum of direct and indirect effect. Total effect represents the total influence of the independent variable on the dependent variable, and indirect effect denotes the influence of the independent variable on the dependent variable via the role of the mediating variable, while direct effect represents the influence of the independent variable on the dependent variable without the role of the mediating variable (i.e., the path coefficient as shown in the model path figure).

Firstly, to study the relationships between environments and health, according to the model fitting results of low-aged (aged 60-69) group, only the positive effect of landscape environment on their health was significant. Furthermore, we examined the hypotheses about the mediating effects of social participation and outdoor activity. The results showed that only the total effect and the direct effect of landscape environment on health of older adults were significant, while all the indirect effects were not. It implied that the mediating role of lifestyle did not exist, so all the hypotheses of $\mathrm{H} 1-\mathrm{H} 5$ were rejected in low-aged group model. This indicated that the effects of the neighborhood environment on health of low-aged (aged 60-69) older adults were not affected by lifestyle. Figure 3 shows more details. 


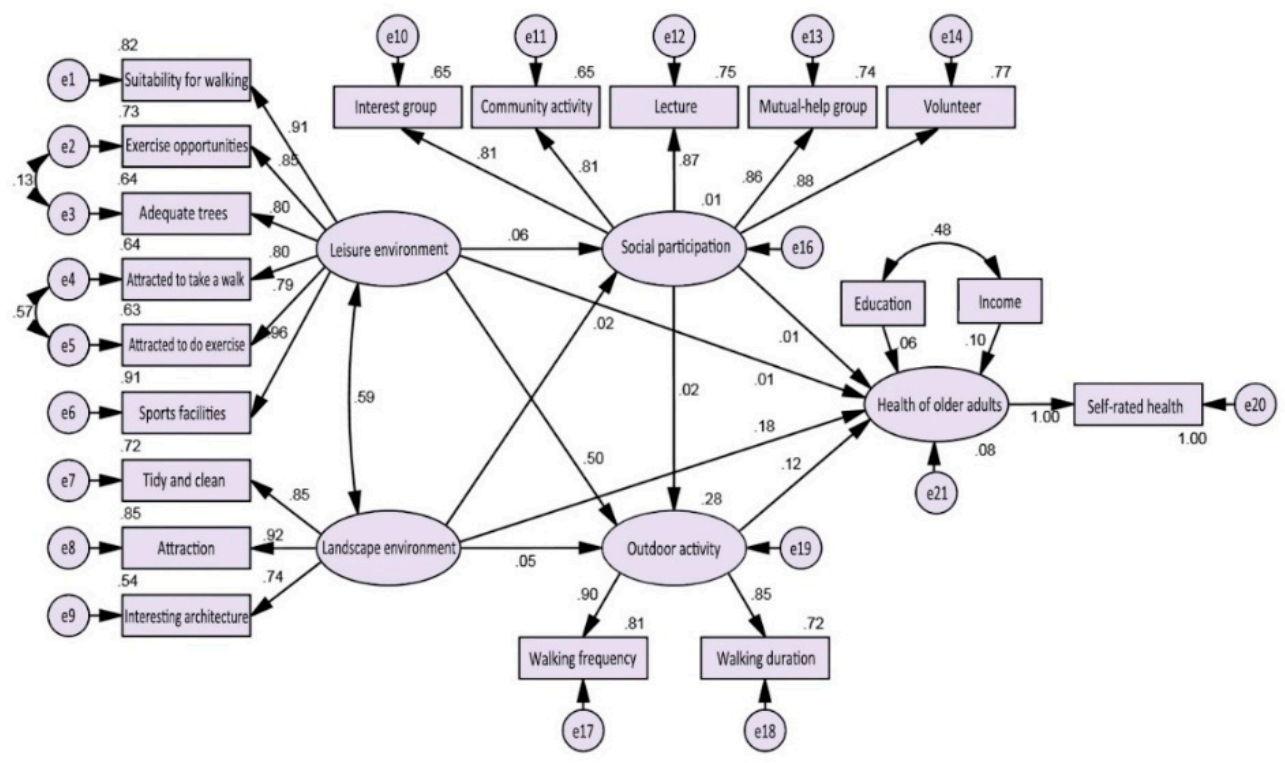

Figure 3. Standardization coefficients for low-aged group model.

Secondly, we continued to focus on the relations between environments and health. As revealed by the fitting results of middle-aged (aged 70-79) group, leisure environment had a significant positive effect on their health, but landscape environment did not. It reflected the difference with the low-aged (aged 60-69) group. The mediating effects of social participation and outdoor activity were further examined. The results clearly showed that the total effect and indirect effect of leisure environment on health of the elderly are significant, while the direct effect is not, indicating that there is a fully mediating effect of lifestyle. Since the effect of leisure environment on social participation was not significant, outdoor activities served as the only one mediator of the relationship between leisure environment and health of the middle-aged (aged 70-79) older adults. In addition, outdoor activities also partly mediated the relation between social participation and health of middle-aged (aged 70-79) older adults. Therefore, $\mathrm{H} 1$ and $\mathrm{H} 5$ were accepted, but $\mathrm{H} 2-\mathrm{H} 4$ were rejected. It suggested that the health of middle-aged (aged 70-79) older adults is not directly affected by neighborhood environment, but completely by the mediating role of outdoor activities. Figure 4 shows more details.

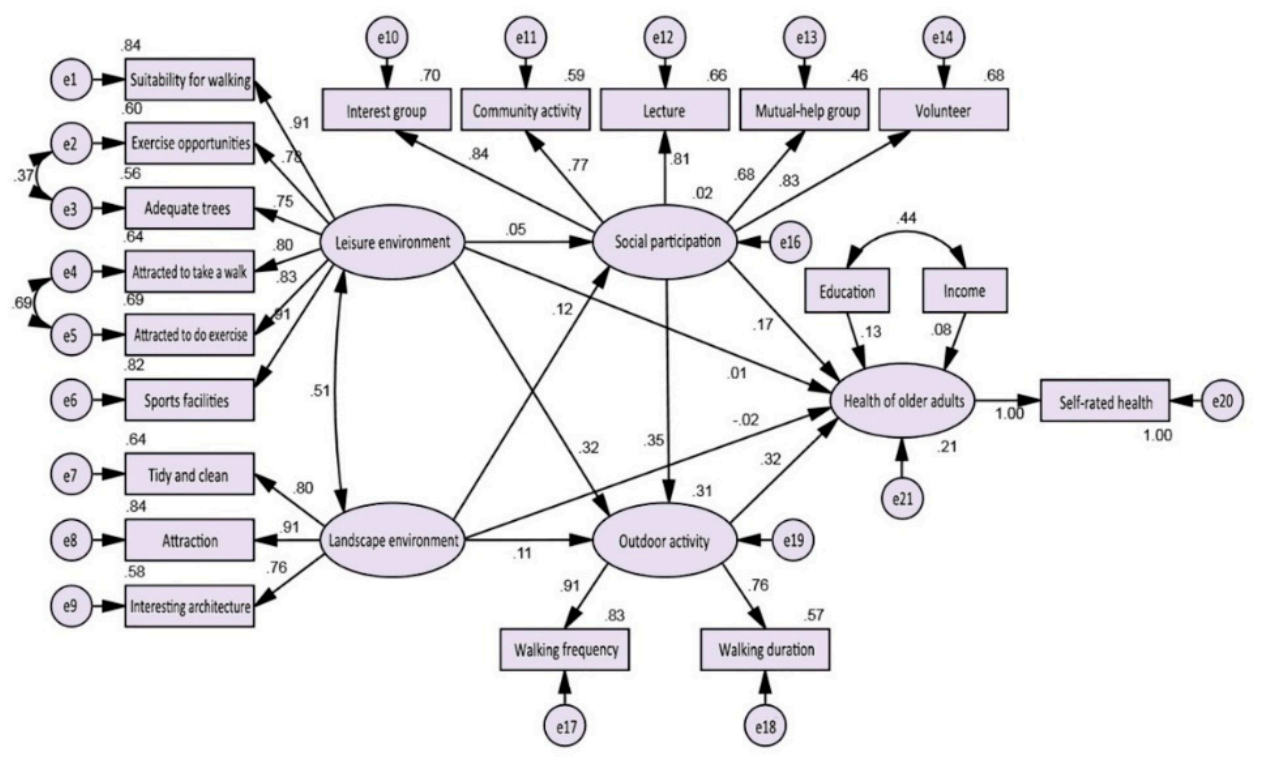

Figure 4. Standardization coefficients for middle-aged group model. 
Finally, considering the fitting results of high-aged (aged 80+) group, we found that in addition to outdoor activity, the positive effects of leisure environment, landscape environment, and social participation on their health were significant. Among them, social participation had the greatest effect. This is quite different from low-aged (aged 60-69) and middle-aged (aged 70-79) group. Next, we examined the mediating effects of social participation and outdoor activity. The results showed that leisure environment did not have direct effect on health of high-aged (aged 80+) older adults, but by the fully mediating effect of social participation. Meanwhile, landscape environment and social participation had only direct effects on their health. Accordingly, all the hypotheses except $\mathrm{H} 3$ were rejected in the high-aged group model. In contrast to the low-aged (aged 60-69) and middle-aged (aged 70-79) group, the older adults in high-aged (aged 80+) group were more dependent on the support of social participation, which not only had direct effect on their health, but also served as a mediator of relationship between neighborhood environment and health. Figure 5 shows more details.

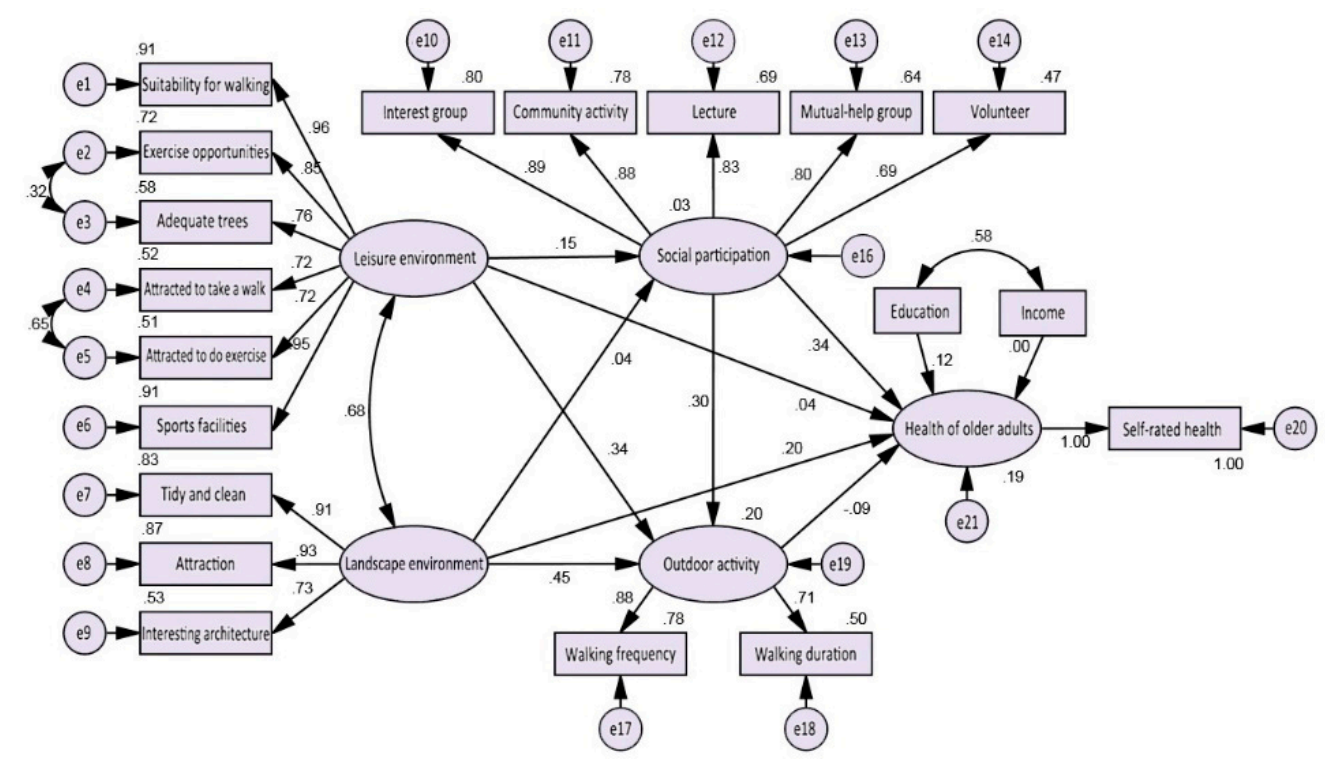

Figure 5. Standardization coefficients for high-aged group model.

\section{Conclusions and Discussion}

This study aimed to promote active aging and the construction of the age-friendly communities. The prime theoretical foundation of the research is the Ecological Model of Aging. We discussed the complex relations between neighborhood environment, lifestyle and the health of older adults, and compared the discrepancy of older adults in different age groups. According to the results of our study, the active lifestyle of older adults, outdoor activity and social participation, were mediators of the relationship between neighborhood environment and health in different age groups. Meanwhile, the paths of "neighborhood environment-lifestyle-health of older adults" model showed significant discrepancy among older adults in different age groups.

The low-aged (aged 60-69) older adults, rely more on the sensory comfort provided by landscape environment and the exercise of physical functions. For middle-aged (aged 70-79) older adults, their health depends more on the support of leisure environment for outdoor activity and social participation. For high-aged (aged 80+) older adults, their health is subject to the support of leisure environment for social participation. This conclusion confirmed the necessity to study neighborhood environment and health of older adults in different age groups. As proposed by Germain et al. [60], ignoring the influence of age discrepancy may bring about biased and even erroneous conclusions in older adults' health and welfare-related research.

"Neighborhood environment-lifestyle-health of older adults" model described the sophisticated relation among various factors, and stressed on the importance of lifestyle in the neighborhood 
ecosystem. Despite the positive or mediating effects of lifestyle on health were different in age groups, some rules can be still seen from such complex relations. In general, leisure environment has an indirect effect on the health of older adults by mediating role of lifestyle, while landscape environment has a direct effect on it.

The discrepancy among older adults of different ages in paths of the model "neighborhood environment-lifestyle-the health of older adults" revealed that pertinent opinions and strategies must be proposed in accordance with various group traits to boost health of older adults in China generally. For low-aged (aged 60-69) group, besides the cultivation of personal healthy habits such as physical exercise, government departments should help improve the landscape environment of their residential communities. For middle-aged (aged 70-79) group, efforts should be made to increase their outdoor activity intensity, reinforce leisure environment quality, and organize activities to promote social participation. For high-aged (aged 80+) group, it is imperative to build a friendlier atmosphere in neighborhood to satisfy their urgent demands for social participation and further contribute to their health.

Additionally, this study verified the importance of neighborhood environment to lifestyle and health of older adults, provided new thoughts for the solution of government elderly-care problems, as well as offer new reference to the improvement of relevant elderly-care public policies. Governments of all the countries, especially in China, should not just focus on the elderly-care service, medical treatment, insurance problems, but also pay more attention to the building of the age-friendly communities and put neighborhood environment optimization and cultivation of the interaction atmosphere on the agenda.

It is important to note several limitations of this study. Firstly, the survey of neighborhood environment is primarily based on subjective assessment, which need more in-depth investigation and more detailed spatial analysis. Moreover, the mere provision of outdoor amenities is often not a sufficient measure of environment quality, and it should include more objective assessment indicators concerning accessibility, aesthetics, and interactivity, etc. To gain deeper insights and more comprehensive knowledge about the influential mechanism of neighborhood environment on the health of older adults, follow-up studies should scientifically and systematically combine the neighborhood environment subjective assessment with objective assessment. Secondly, social participation and lifestyle are issues that cannot be addressed solely through surveys and statistical methods, which require further interviews, fieldwork, and some big data on individual behaviors. Thirdly, the neighborhood sample size is rather limited. Since the researcher just carries out the survey in Xinhua Sub-district, Changning District of Shanghai, the representativeness of research conclusions is not adequate. More empirical studies need to be developed in the future. Finally, the representativeness of older adult samples can be further improved. Although the study has taken into full consideration of the diversity of the geographical location, transportation convenience, and completion in respect of the selection of the neighborhoods, it still failed to strictly comply with random sampling principle. Therefore, the structure of final older adult samples is uncertain, which is in need for further improvement by future research.

Author Contributions: Conceptualization: Z.Z. and L.Y.; Data curation: Z.Z.; Formal analysis, Z.Z. and L.Y.; Methodology: Z.Z.; Validation: L.Y.; Investigation, Z.Z.; Software: Z.Z.; Resources: Z.Z.; Writing一original draft preparation: Z.Z.; writing—review and editing: L.Y.; Visualization: Z.Z.; Supervision: L.Y.; Project administration: L.Y.; Funding acquisition: L.Y.

Funding: This research was funded by the Major Project of the National Natural Science Foundation of China (Grant No. 71490735), and the Youth Project of Humanities and Social Sciences Foundation of Ministry of Education of China (Grant No. 14YJCZH179).

Acknowledgments: We wish to acknowledge our appreciation for great helpful suggestions of Professor Xizhe Peng and the anonymous reviewers.

Conflicts of Interest: The authors declare no conflict of interest. 


\section{References}

1. Word Health Organization. Active Ageing: A Policy Framework; World Health Organization: Geneva, Switzerland, 2002.

2. World Health Organization. Global Age-Friendly Cities: A Guide; World Health Organization: Geneva, Switzerland, 2007.

3. Plouffe, L.; Kalache, A. Towards global age-friendly cities: Determining urban features that promote active aging. J. Urban Health 2010, 87, 733-739. [CrossRef] [PubMed]

4. Smith, R.J.; Lehning, A.J.; Dunkle, R.E. Conceptualizing age-friendly community characteristics in a sample of urban elders: An exploratory factor analysis. J. Gerontol. Soc. Work 2013, 56, 90-111. [CrossRef] [PubMed]

5. Lawton, M.P.; Nahemow, L. Ecology and the aging process. In The Psychology of Adult Development and Aging; Eisdorfer, C., Lawton, M.P., Eds.; American Psychological Association: Washington, DC, USA, 1973; pp. 619-674.

6. Menec, V.H.; Nowicki, S. Examining the relationship between communities' 'age-friendliness' and life satisfaction and self-perceived health in rural Manitoba, Canada. Rural Remote Health 2014, 14, 2594. [PubMed]

7. Moore, K.D. An ecological framework of place: Situating environmental gerontology within a life course perspective. Int. J. Aging Hum. Dev. 2014, 79, 183-209. [CrossRef]

8. De Vries, S.; Verheij, R.A.; Groenewegen, P.P.; Spreeuwenberg, P. Natural environments-Healthy environments? An exploratory analysis of the relationship between greenspace and health. Environ. Plan. A 2003, 35, 1717-1731. [CrossRef]

9. Xue, X.D.; Cheng, M.M. A study on relationship of social capital, health and happiness among rural elderly in China: Empirical analysis based on survey data in Hubei and Henan province. Econ. Manag. J. 2012, 34, 166-175. (In Chinese)

10. Mulhern, B.; Shah, K.; Janssen, M.F.B.; Longworth, L.; Ibbotson, R. Valuing health using time trade-off and discrete choice experiment methods: Does dimension order impact on health state values? Value Health 2016, 19, 210-217. [CrossRef]

11. Glicksman, A.; Ring, L.; Kleban, M.; Hoffman, C. Is “walkability" a useful concept for gerontology? J. Hous. Elder. 2013, 27, 241-254. [CrossRef]

12. Wang, Y.; Chen, Y.C.; Shen, H.W.; Morrow-Howell, N. Neighborhood and depressive symptoms: A comparison of rural and urban Chinese older adults. Gerontologist 2017, 58, 68-78. [CrossRef]

13. Rantakokko, M.; Iwarsson, S.; Kauppinen, M.; Leinonen, R.; Heikkinen, E.; Rantanen, T. Quality of life and barriers in the urban outdoor environment in old age. J. Am. Geriatr. Soc. 2010, 58, 2154-2159. [CrossRef]

14. Lehning, A.J. Local and regional governments and age-friendly communities: A case study of the San Francisco Bay Area. J. Aging Soc. Policy 2014, 26, 102-116. [CrossRef]

15. Word Health Organization. Good Health Adds Life to Years: Global Brief for World Health Day 2012; World Health Organization: Geneva, Switzerland, 2012.

16. Shanghai Bureau of Statistics. Shanghai Statistical Yearbook; Shanghai Bureau of Statistics: Shanghai, China, 2018.

17. Scheidt, R.J.; Windley, P.G. Environmental gerontology: Progress in the post-Lawton era. In Handbook of the Psychology of Aging, 6th ed.; Birren, J., Schaie, K.W., Eds.; Academic Press: San Diego, CA, USA, 2006; pp. 105-125.

18. Bell, S.A.; Bern-Klug, M.; Kramer, K.W.; Saunders, J.B. Most nursing home social service directors lack training in working with lesbian, gay, and bisexual residents. Soc. Work Health Care 2010, 49, 814-831. [CrossRef]

19. Berke, E.M.; Koepsell, T.D.; Moudon, A.V.; Hoskins, R.E.; Larson, E.B. Association of the built environment with physical activity and obesity in older persons. Am. J. Public Health 2007, 97, 486-492. [CrossRef]

20. Echeverria, S.E.; Diez-Roux, A.V.; Link, B.G. Reliability of self reported neighborhood characteristics. J. Urban Health 2004, 81, 682-701. [CrossRef]

21. Gao, J.; Fu, H.; Li, J.; Jia, Y. Association between social and built environments and leisure-time physical activity among Chinese older adults: A multilevel analysis. BMC Public Health 2015, 15, 1317. [CrossRef]

22. Humpel, N.; Owen, N.; Leslie, E. Environmental factors associated with adults' participation in physical activity: A review. Am. J. Prev. Med. 2002, 22, 188-199. [CrossRef] 
23. Lee, J.A.; Park, J.H.; Kim, M. Social and physical environments and self-rated health in urban and rural communities in Korea. Int. J. Environ. Res. Public Health 2015, 12, 14329-14341. [CrossRef]

24. Mujahid, M.S.; Diez-Roux, A.V.; Morenoff, J.D.; Raghunathan, T. Assessing the measurement properties of neighborhood scales: From psychometrics to ecometrics. Am. J. Epidemiol. 2007, 165, 858-867. [CrossRef]

25. Cockerham, W.C.; Scambler, G. Medical sociology and sociological theory. In The New Blackwell Companion to Medical Sociology; Cockerham, W.C., Ed.; Wiley-Blackwell: Chichester, NH, USA, 2009.

26. McNeill, L.H.; Kreuter, M.W.; Subramanian, S.V. Social environment and physical activity: A review of concepts and evidence. Soc. Sci. Med. 2006, 63, 1011-1022. [CrossRef]

27. Dunstan, F.; Fone, D.L.; Glickman, M.; Palmer, S. Objectively measured residential environment and self-reported health: A multilevel analysis of UK census data. PLoS ONE 2013, 8, e69045. [CrossRef]

28. Lehning, A.J.; Smith, R.J.; Dunkle, R.E. Age-friendly environments and self-rated health: An exploration of Detroit elders. Res. Aging 2014, 36, 72-94. [CrossRef]

29. Chen, Y.; While, A.E.; Hicks, A. Self-rated health and associated factors among older people living alone in Shanghai. Geriatr. Gerontol. Int. 2015, 15, 457-464. [CrossRef]

30. Cummins, S.; Stafford, M.; Macintyre, S.; Marmot, M.; Ellaway, A. Neighbourhood environment and its association with self rated health: Evidence from Scotland and England. J. Epidemiol. Community Health 2005, 59, 207-213. [CrossRef]

31. Morrow-Howell, N.; Hinterlong, J.; Sherraden, M. Productive Aging: Concepts and Challenges; Johns Hopkins University Press: Baltimore, MD, USA, 2001.

32. Morrow-Howell, N.; Gehlert, S. Social engagement and a healthy aging society. In Public Health for an Aging Society; Prohaska, T.R., Anderson, L.A., Binstock, R.H., Eds.; Johns Hopkins University Press: Baltimore, MD, USA, 2012; pp. 205-227.

33. Glass, T.A.; De Leon, C.F.M.; Bassuk, S.S.; Berkman, L.F. Social engagement and depressive symptoms in late life: Longitudinal findings. J. Aging Health 2006, 18, 604-628. [CrossRef]

34. Ichida, Y.; Hirai, H.; Kondo, K.; Kawachi, I.; Takeda, T.; Endo, H. Does social participation improve self-rated health in the older population? A quasi-experimental intervention study. Soc. Sci. Med. 2013, 94, 83-90. [CrossRef]

35. Vogelsang, E.M. Older adult social participation and its relationship with health: Rural-urban differences. Health Place 2016, 42, 111-119. [CrossRef]

36. Nishimori, T.; Imaoka, M.; Kuremoto, T. Variance of divided step length in relation to walking speed in the elderly in a geriatric health services facility. Physiotherapy 2015, 101, e1097-e1098. [CrossRef]

37. Bellelli, G.; Noale, M.; Guerini, F.; Turco, R.; Maggi, S.; Crepaldi, G.; Trabucchi, M. A prognostic model predicting recovery of walking independence of elderly patients after hip-fracture surgery. An experiment in a rehabilitation unit in Northern Italy. Osteoporos. Int. 2012, 23, 2189-2200. [CrossRef]

38. Hatta, A.; Nishihira, Y.; Higashiura, T. Effects of a single bout of walking on psychophysiologic responses and executive function in elderly adults: A pilot study. Clin. Interv. Aging 2013, 8, 945-952. [CrossRef]

39. Yaffe, K.; Barnes, D.; Nevitt, M.; Lui, L.; Covinsky, K. A prospective study of physical activity and cognitive decline in elderly women: Women who walk. Arch. Intern. Med. 2001, 161, 1703-1708. [CrossRef]

40. Zhao, W.; Ukawa, S.; Kawamura, T.; Wakai, K.; Ando, M.; Tsushita, K.; Tamakoshi, A. Health benefits of daily walking on mortality among younger-elderly men with or without major critical diseases in the new integrated suburban seniority investigation project: A prospective cohort study. J. Epidemiol. 2015, 25, 609-616. [CrossRef]

41. Abate, M.; Salini, V.; Schiavone, C. Achilles tendinopathy in elderly subjects with type II diabetes: The role of sport activities. Aging Clin. Exp. Res. 2016, 28, 355-358. [CrossRef]

42. Rizzello, S.; Turvani, M. Subjective diversity and social learning: A cognitive perspective for understanding institutional behavior. Const. Political Econ. 2002, 13, 197-210. [CrossRef]

43. Gehl, J. Life between Buildings: Using Public Space; Island Press: Washington, DC, USA, 2011.

44. King, A.C.; Sallis, J.F.; Frank, L.D.; Saelens, B.E.; Cain, K.; Conway, T.L.; Chapman, J.E.; Ahn, D.K.; Kerr, J. Aging in neighborhoods differing in walkability and income: Associations with physical activity and obesity in older adults. Soc. Sci. Med. 2011, 73, 1525-1533. [CrossRef]

45. Barnett, A.; Cerin, E.; Zhang, C.J.; Sit, C.H.; Johnston, J.M.; Cheung, M.M.; Lee, R.S. Associations between the neighbourhood environment characteristics and physical activity in older adults with specific types of chronic conditions: The ALECS cross-sectional study. Int. J. Behav. Nutr. Phys. Act. 2016, 13, 53. [CrossRef] 
46. Cerin, E.; Macfarlane, D.J.; Ko, H.H.; Chan, K.C.A. Measuring perceived neighbourhood walkability in Hong Kong. Cities 2007, 24, 209-217. [CrossRef]

47. Zhao, Y.; Chung, P.K. Neighborhood environment walkability and health-related quality of life among older adults in Hong Kong. Arch. Gerontol. Geriatr. 2017, 73, 182-186. [CrossRef]

48. Emlet, C.A.; Moceri, J.T. The importance of social connectedness in building age-friendly communities. J. Aging Res. 2012, 2012, 173247. [CrossRef]

49. Scharlach, A.E.; Lehning, A.J. Ageing-friendly communities and social inclusion in the United States of America. Ageing Soc. 2013, 33, 110-136. [CrossRef]

50. Wahl, H.; Oswald, F. Environmental perspectives on ageing. In The SAGE Handbook of Social Gerontology; Dannefer, D., Phillipson, C., Eds.; SAGE Publications Ltd.: London, UK, 2010; pp. 111-124.

51. Joseph, A.; Zimring, C. Where active older adults walk: Understanding the factors related to path choice for walking among active retirement community residents. Environ. Behav. 2007, 39, 75-105. [CrossRef]

52. Li, F.; Fisher, K.J.; Brownson, R.C.; Bosworth, M. Multilevel modelling of built environment characteristics related to neighbourhood walking activity in older adults. J. Epidemiol. Community Health 2005, 59, 558-564. [CrossRef]

53. Theodoropoulou, E.; Stavrou, N.A.; Karteroliotis, K. Neighborhood environment, physical activity, and quality of life in adults: Intermediary effects of personal and psychosocial factors. J. Sport Health Sci. 2017, 6, 96-102. [CrossRef]

54. Jylhä, M. What is self-rated health and why does it predict mortality? Towards a unified conceptual model. Soc. Sci. Med. 2009, 69, 307-316. [CrossRef]

55. Pagotto, V.; Bachion, M.M.; da Silveira, E.A. Self-assessment of health by older Brazilians: Systematic review of the literature. Rev. Panam. Salud Publica 2013, 33, 302-311. [CrossRef]

56. Tsai, A.G.; Boyle, T.F.; Hill, J.O.; Lindley, C.; Weiss, K. Changes in obesity awareness, obesity identification, and self-assessment of health: Results from a statewide public education campaign. Am. J. Health Educ. 2014, 45, 342-350. [CrossRef]

57. Wu, S.; Wang, R.; Zhao, Y.; Ma, X.; Wu, M.; Yan, X.; He, J. The relationship between self-rated health and objective health status: A population-based study. BMC Public Health 2013, 13, 320. [CrossRef]

58. Maddox, G.L.; Douglass, E.B. Self-assessment of health: A longitudinal study of elderly subjects. J. Health Soc. Behav. 1973, 14, 87-93. [CrossRef]

59. Ma, S.; Wang, X. Key points of care and age division in old age. J. Pract. Med Tech. 2008, 15, 4311-4312. (In Chinese)

60. Germain, C.M.; Vasquez, E.; Batsis, J.A.; McQuoid, D.R. Sex, race and age differences in muscle strength and limitations in community dwelling older adults: Data from the Health and Retirement Survey (HRS). Arch. Gerontol. Geriatr. 2016, 65, 98-103. [CrossRef]

(C) 2019 by the authors. Licensee MDPI, Basel, Switzerland. This article is an open access article distributed under the terms and conditions of the Creative Commons Attribution (CC BY) license (http://creativecommons.org/licenses/by/4.0/). 